Check for updates

Cite this: RSC Adv., 2019, 9, 11013

Received 27th February 2019

Accepted 29th March 2019

DOI: $10.1039 / c 9 r a 01500 k$

rsc.li/rsc-advances

\section{Novel waterborne UV-curable coatings based on hyperbranched polymers via electrophoretic deposition $\uparrow$}

\begin{abstract}
Junhua Chen, ${ }^{\text {ac }}$ Kaimei Peng (D) *b and Weiping Tu (DD *a
Two modified types of hyperbranched polymer were successfully prepared using hyperbranched polyether (HBPE) as a matrix, cis-5-norbornene-endo-2,3-dicarboxylic anhydride (CDA) or o-phthalic anhydride (PA) as a modifier and by grafting an NCO-terminated compound (IPDI-HEA). The modified hyperbranched polymers were incorporated into a typical water-soluble polyacrylate (WPA) as crosslinkers to develop high-performance waterborne UV-curable coatings via electrophoretic deposition (EPD). Although the particle size of the electrophoretic dispersion increased from $43.8 \mathrm{~nm}$ to $164 \mathrm{~nm}$, no microphase separation occurred, and the smooth SEM images of the coatings confirmed their uniformity. The rate of photopolymerization $\left(R_{\mathrm{p}}\right)$ and percentage conversion of the double bonds increased with increasing active unsaturated double bond content, and were partially affected by steric effects. Thermal gravity analysis and tensile tests indicated that the UV-curable EPD coating films exhibited better thermal stability due to their hyperbranched structure, soft and hard segment content and crosslinking density. The coated tin plate could resist chemical corrosion after immersion in $\mathrm{NaCl}$ solution. The coatings demonstrated strong adhesion to extremely bent tin plates and outstanding tolerance to knife-scratches and impact. This is a promising method for the design of desirable coatings in the EPD industry.
\end{abstract}

\section{Introduction}

Electrophoretic deposition (EPD) techniques can be extensively utilized for industrial coatings onto conductive substrates, such as in automotives, appliances, instruments, etc., which is attributed to its unique features of versatility for complex shapes, controllability and low cost. ${ }^{\mathbf{1 - 4}}$ EPD techniques are environmentally friendly, scalable, less labor-intensive, and can be used to fabricate a uniform coating by controlling the deposition time and applied voltage. ${ }^{2,5,6}$ Cathodic EPD coatings possess better chemical shielding and avoid the disadvantages of anodic EPD coatings of substrates being corroded and discolored. ${ }^{7}$ For typical EPD coatings, the blocked isocyanates are deblocked and then form free isocyanate groups at $160-180{ }^{\circ} \mathrm{C}$ for accelerating the crosslinking and curing reaction. ${ }^{8}$ Automotive parts containing plastics, rubber, etc. are easily deformed when baked at high temperatures, which also result in high energy consumption. Compared to thermal curing, UV

${ }^{a}$ School of Chemistry and Chemical Engineering, South China University of Technology, Guangzhou 510640, China.E-mail: cewptu@yeah.net

${ }^{b}$ School of Chemistry and Chemical Engineering, Qiannan Normal University for Nationalities, Duyun 558000, China.E-mail: scutpkm@163.com

${ }^{c}$ School of Environmental and Chemical Engineering, Zhaoqing University, Zhaoqing 526061, China

† Electronic supplementary information (ESI) available. See DOI: 10.1039/c9ra01500k curing has been employed in an increasing number of industrial applications over the past decade owing to its unique benefits, such as solvent-free formulations (less VOC emissions), high-cure speed and low-temperature processing with low energy consumption. ${ }^{9,10}$ Consequently, a new approach is the combination of the EPD technique and UV-curing. ${ }^{11}$

The aim of investigations on UV-curable EPD coatings is to reduce the moisture content of wet films, enhancing uniformity and the decorative nature of coatings. ${ }^{12,13}$ Some investigators have developed UV-curable EPD coatings based on different resin systems to analyze the kinetics and mechanism of the ultraviolet curing reaction, with the addition of an acryl functional polymer as a curing agent. ${ }^{12-14}$ The coatings comprised aqueous emulsions and aqueous dispersions, which present reactive diluent bearing unsaturated double bonds for crosslinking and hydrophilic groups for dispersion in water. ${ }^{12}$ But waterborne EPD coatings have some shortcomings such as poor mechanical properties, long drying times, and weak flexibility. ${ }^{\mathbf{1 0}}$ The major disadvantage for UV systems is that they are mainly composed of high viscosity linear acrylates before being dispersed in water. In order to lower the viscosity, it is necessary to add some active double bond diluent, but which will increase the toxicity. So, the selection of less polluting, low viscosity and active double bond diluent is particularly important.

Hyperbranched polymers (HBPs) have attracted great interest in recent years due to the relatively new and simple process at low cost. ${ }^{15,16}$ Hyperbranched polymers have various 
unique properties, such as low viscosity, high activity and tailorable compatibility, which make them possible candidates as reactive diluents to be used in UV-curable waterborne EPD dispersion. ${ }^{17,18}$ Liu prepared a new photo-curable composition of hyperbranched purethane acrylate/nano-silica for flexographic ink, which showed excellent water resistance and outstanding durability. ${ }^{17}$ Yang introduced ultraviolet curing coatings based on a cardanol-based acrylate oligomer, which exhibited excellent physical properties. In addition, the raw materials were green and renewable. ${ }^{19}$ Shi synthesized different ionomers selected as aqueous UV-curing coatings bearing hyperbranched urethane acrylates, which was to investigate the change in the particle size of dispersions and the thermal properties of the UV-cured films. ${ }^{20}$ Overall, although hyperbranched polymers as reactive diluents for waterborne UVcurable EPD coatings have tremendous growth potential, research on their application has yet to start.

To sum up, we have prepared novel waterborne UV-curable coatings via electrophoretic deposition based on two modified hyperbranched polymers with a flexible aliphatic chain structure (CDA) and a rigid benzene ring (PA) in this article, which were named for curing MWPA-CDA66, MWPA-CDA39, and MWPA-CDA93 (PA was the same), with the individual ratios $6: 6,3: 9$, and $9: 3$ for the double bond to carboxyl watersoluble group at the terminals.

\section{Experimental}

\subsection{Materials}

2-Hydroxypropyl methacrylate (HPMA, 80\%), butyl acrylate (BA, 98\%), 2-(dimethylamino)ethyl methacrylate (DMAEMA, 99\%), 2hydroxyethyl acrylate (HEA, 97\%), methyl 2-methylacrylate (MMA, 99\%), styrene (St, 95\%) and 2,2'-azobis(2-methylpropionitrile) (AIBN) were purchased from Aladdin Industrial Corporation. Isophorone diisocyanate (IPDI, NCO $\% \geq 37.5 \%$ ) was purchased from Bayer AG. Hyperbranched aliphatic polyester (HBPE) was supplied by Wuhan Hyperbranched Polymers Science \& Technology Co., Ltd, China. cis-5-Norbornene-endo-2,3-dicarboxylic anhydride (abbreviated to CDA), o-phthalic anhydride (abbreviated to PA), 1,6-hexanediol diacrylate (HDDA) and 2-hydroxy-2methylpropiophenone (Darocur 1173) were purchased from Aladdin Chemistry Co., Ltd. Dibutyltin dilaurate (DBTDL), 2,6-ditert-butyl- $p$-cresol (BHT) and tin(II) chloride were provided by Macklin Chemical Ltd.

\subsection{Synthesis of water-soluble polyacrylate (WPA)}

A typical WPA was prepared via the three steps shown in Fig. 1, IPDI (10.01 g, $0.045 \mathrm{~mol})$ was dissolved in ethyl acetate $(5 \mathrm{~mL})$, and then DBTDL $(4 \mathrm{mg})$ and BHT $(71.8 \mathrm{mg})$ were added in a dry nitrogen atmosphere. This was subsequently heated to $60{ }^{\circ} \mathrm{C}$. After dropping HEA (5.44 g, $0.045 \mathrm{~mol}$ ) into the above mixture slowly over $1 \mathrm{~h}$, the reaction continued for $1.5 \mathrm{~h}$. Until the theoretical value of the isocyanate groups could be detected using the di- $n$-butylamine method, the NCOterminated compound (IPDI-HEA) was obtained as shown in Fig. 2(III). ${ }^{21,22}$
In the second step, a four-necked round-bottom flask (500 $\mathrm{mL})$ at room temperature bearing ethyl acetate $(60 \mathrm{~mL})$ was used to eliminate oxygen by adding nitrogen for $30 \mathrm{~min}$, and was subsequently heated to $80{ }^{\circ} \mathrm{C}$. DMAEMA (16 mL), MMA (24.0 $\mathrm{mL}$ ), BA (25 mL), HPMA (8 mL), St (7 mL), and AIBN (5.0 g) were dissolved in ethyl acetate (EAC, $60 \mathrm{~g}$ ). By adding mixed solution to the reaction dropwise, it was continued over $12 \mathrm{~h}$ until complete polymerization. The crude reaction mixture was partially distilled under reduced pressure to obtain about $70 \mathrm{wt} \%$ solution.

In the third step, IPDI-HEA (15.45 g), DBTDL (0.01 wt\%) and DBHT $(0.2 \mathrm{wt} \%)$ were dissolved in EAC $(5 \mathrm{~g})$, then the mixed solution was added to the crude reaction mixture at $60{ }^{\circ} \mathrm{C}$. Once the peaks in the infrared spectra for the NCO groups had completely disappeared, the product mixture's temperature was finally decreased to $50{ }^{\circ} \mathrm{C}$ and it was neutralized with 2hydroxypropanoic acid, and WPA was obtained. The WPA mixture was added into hexane to precipitate the polymer. The precipitate was then centrifuged at high speed. The precipitate was re-dissolved in THF, and the resulting solution was added to an equal volume of hexane and diethyl ether to obtain the precipitated polymer. The sample was finally evaporated under vacuum to give a purified product.

\subsection{Preparation of modified hyperbranched polyester}

The chemical structure of HBPE in Fig. 2(I) and the procedure for the synthesis of modified HBPE are shown in Fig. 2(II). HBPE (10.0 g) was dissolved in 1,4-dioxane (50 g), then CDA (3.8 $\mathrm{g}, 23.15 \mathrm{mmol}$ hydroxyl groups) and $\mathrm{SnCl}_{2}$ ( $1 \mathrm{wt} \%$ of total) as the catalyst were added. ${ }^{20,23}$ The reaction mixture was subsequently heated to $100{ }^{\circ} \mathrm{C}$ until the infrared spectra of the anhydride peak at $1790 \mathrm{~cm}^{-1}$ had completely disappeared. A light-yellow highly viscous resin was obtained by evaporating 1,4-dioxane. The final polymer for characterization possessed theoretically six OH end-groups named HBPE-OH66 (all belonging to HBPE-CDA).

In the last synthetic process shown in Fig. 2(IV), the prepolymer synthesized IPDI-HEA bearing DBTDL (0.1 wt\%) was charged into a flask containing HBPE-OH66, and stirred vigorously at $40{ }^{\circ} \mathrm{C}$. Once the infrared spectra peaks for the NCO groups had completely disappeared, the crude polymer mixture was vacuumed to remove volatile impurities at $45{ }^{\circ} \mathrm{C}$ for $4 \mathrm{~h}$ to yield HBPE-CDA-IPDI-HEA [Fig. 2(IV)] as a yellow liquid.

Therefore, the molar ratio of carboxyl group to hydroxyl group after modification of HBPE was $3: 9$ and $9: 3$, yielding the products $\mathrm{HBPE}-\mathrm{OH} 39$ and $\mathrm{HBPE}-\mathrm{OH} 93$, respectively. ${ }^{20}$ HBPE-PA and HBPE-PA-IPDI-HEA were also prepared as above, as shown in Fig. 2(IV).

\subsection{Preparation of UV curing EPD coatings}

The coatings were prepared via the procedure depicted in Fig. 3. The above WPA, modified hyperbranched polyester (30 wt\%, HBPE-CDA-IPDI-HEA or HBPE-PA-IPDI-HEA), Darocur 1173 (5 wt\%) and distilled water were added and mixed thoroughly. After $30 \mathrm{~min}, 15.00 \mathrm{wt} \%$ EPD solution was obtained. Tin plates were immerged into a standard EPD setup for $60 \mathrm{~s}$ with 


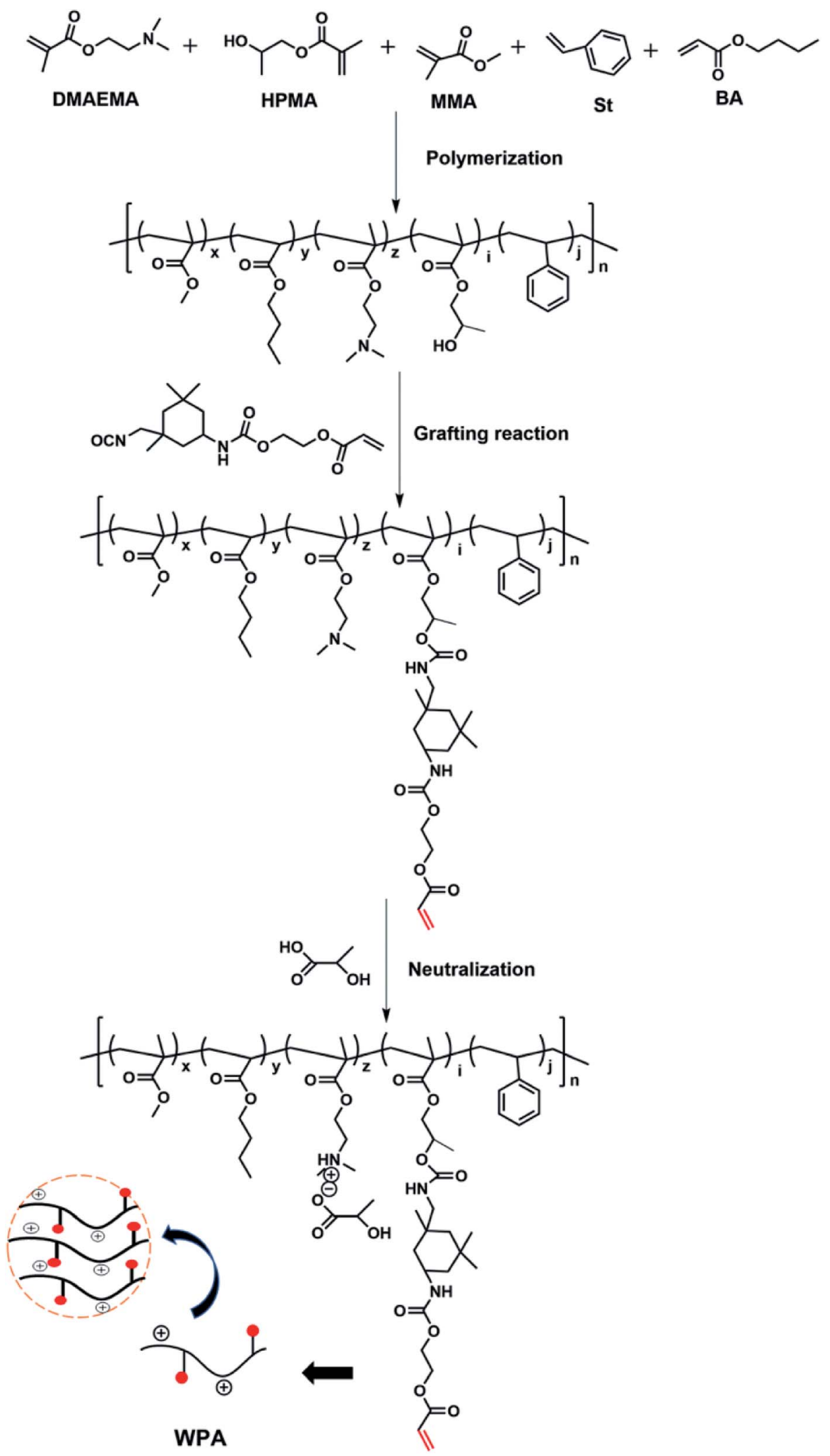

Fig. 1 Synthesis of water-soluble polyacrylate (WPA).

a deposition voltage of $60 \mathrm{~V}$. Plenty of water was used to rinse the EPD coatings, and then they were put in an oven to remove the moisture for a flash-off period of $3 \mathrm{~min}$ at $80^{\circ} \mathrm{C}$. Finally, the dried coatings were completely cured under UV irradiation for $60 \mathrm{~s}$.

\subsection{Characterization methods}

2.5.1 Structural characterization. Fourier transform infrared analysis (FTIR) of all the polymers and monomers was 
(I)

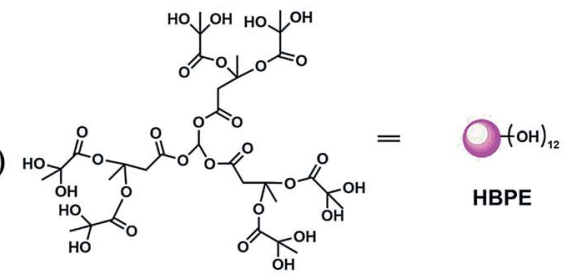

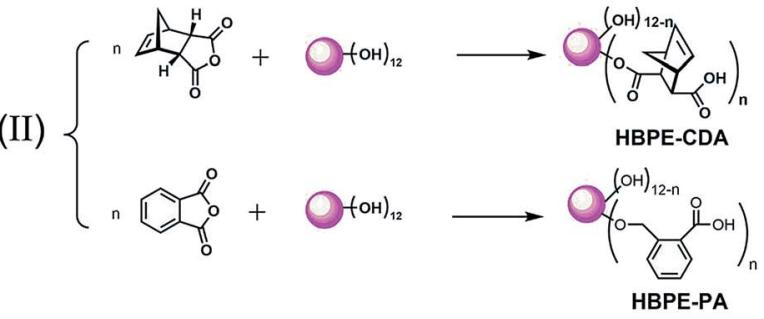

(III)
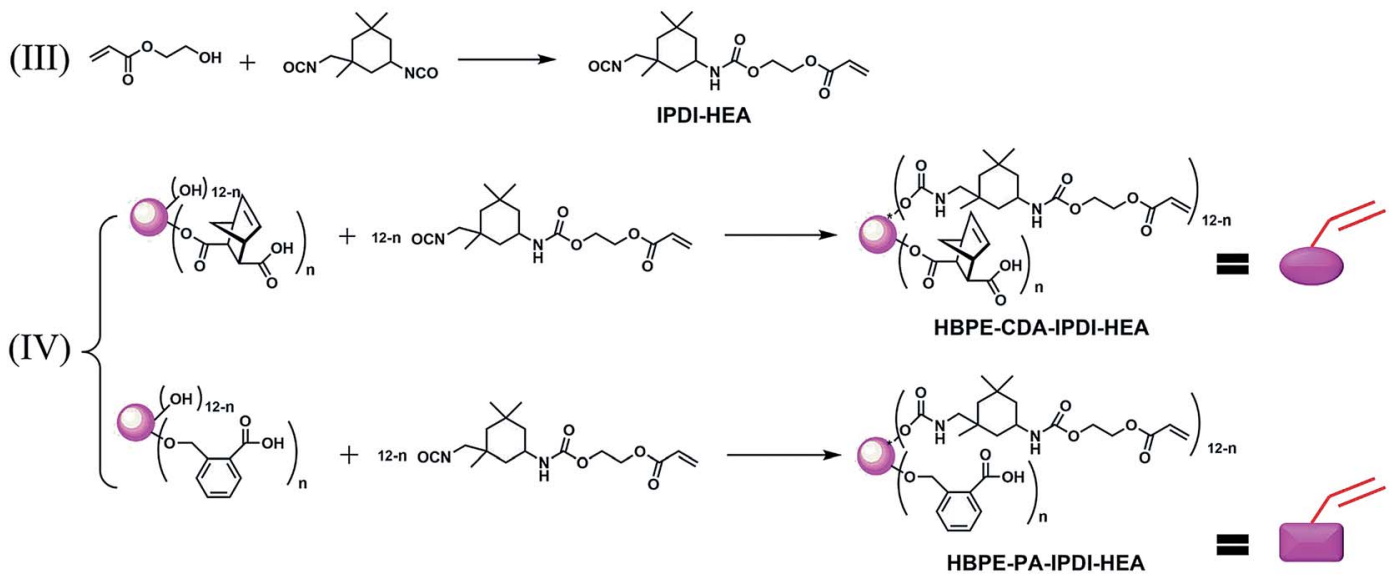

Fig. 2 Synthesis of the modified hyperbranched polyesters. (I) The chemical structure of HBPE; (II) the procedure for synthesis of modified HBPE with CDA and PA; (III) the procedure for synthesis of NCO-terminated compound (IPDI-HEA); (IV) the procedure for synthesis of HBPE-CDAIPDI-HEA and HBPE-PA-IPDI-HEA.

carried out with RFX-65A (Analect, USA). ${ }^{1} \mathrm{H}-\mathrm{NMR}$ spectra were recorded on a DRX-400 spectrometer with 128 scans and a relaxation delay of $3 \mathrm{~s}$, using $\mathrm{CDCl}_{3}$ and DMSO as a solvent.

2.5.2 The aggregation of polymer. The molecular weight of the polymers was measured using size-exclusion chromatography

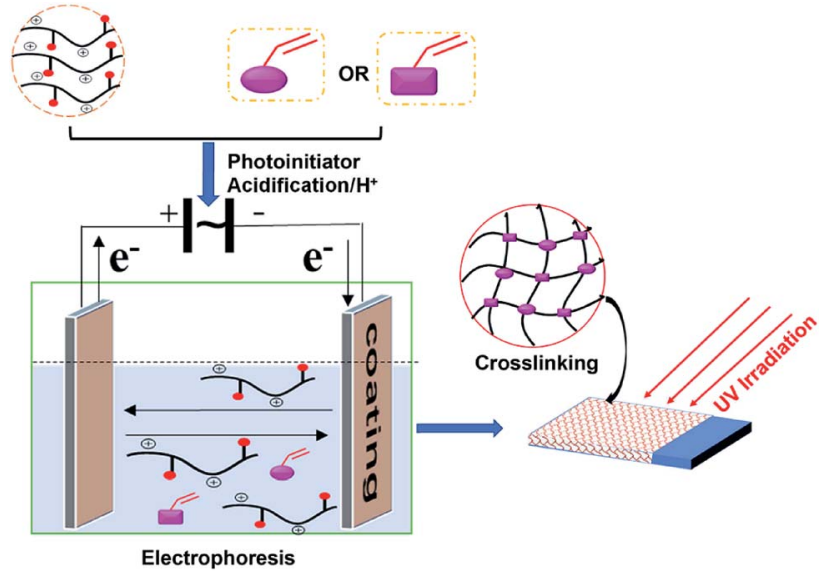

Fig. 3 Illustration of the UV-curing EPD protocol.
(SEC). Tetrahydrofuran (THF) was used as the mobile phase. The aggregate diameter of the EPD micro-emulsion was evaluated via dynamic light scattering (DLS) measurements (ZSE, Malvern Instruments). About $0.1 \mathrm{~mL}$ of sample was diluted to $50 \mathrm{~mL}$ with distilled water.

2.5.3 The photo-curing kinetics. The photo-curing kinetics were determined via a photo-DSC instrument. The samples were a mixture of modified acrylic resin, the modified hyperbranched polyester, HDDA and Darocur 1173. About $5 \mathrm{mg}$ of sample was added into an aluminum pan, and then exposed under a high-pressure $\mathrm{Hg}$ lamp (wavelength range: $200-400 \mathrm{~nm}$ ) for $2 \mathrm{~min}$. The obtained data was analyzed with TA instrument software.

2.5.4 Thermal behavior measurement. The thermal behavior of the coatings was investigated via a differential scanning calorimeter (DSC 200F3 Netzsch). At a heating speed of $10{ }^{\circ} \mathrm{C} \min ^{-1}$ and in a nitrogen atmosphere, the temperature tests were performed in -70 to $250{ }^{\circ} \mathrm{C}$. The thermal stability tests of the samples (about $5 \mathrm{mg}$ ) were conducted through thermogravimetric analysis (TGA, NETZSCH, and TG209F3). The thermal tests were recorded from 25 to $600{ }^{\circ} \mathrm{C}$ with a heating speed of $10{ }^{\circ} \mathrm{C}$ min under $\mathrm{N}_{2}$. 

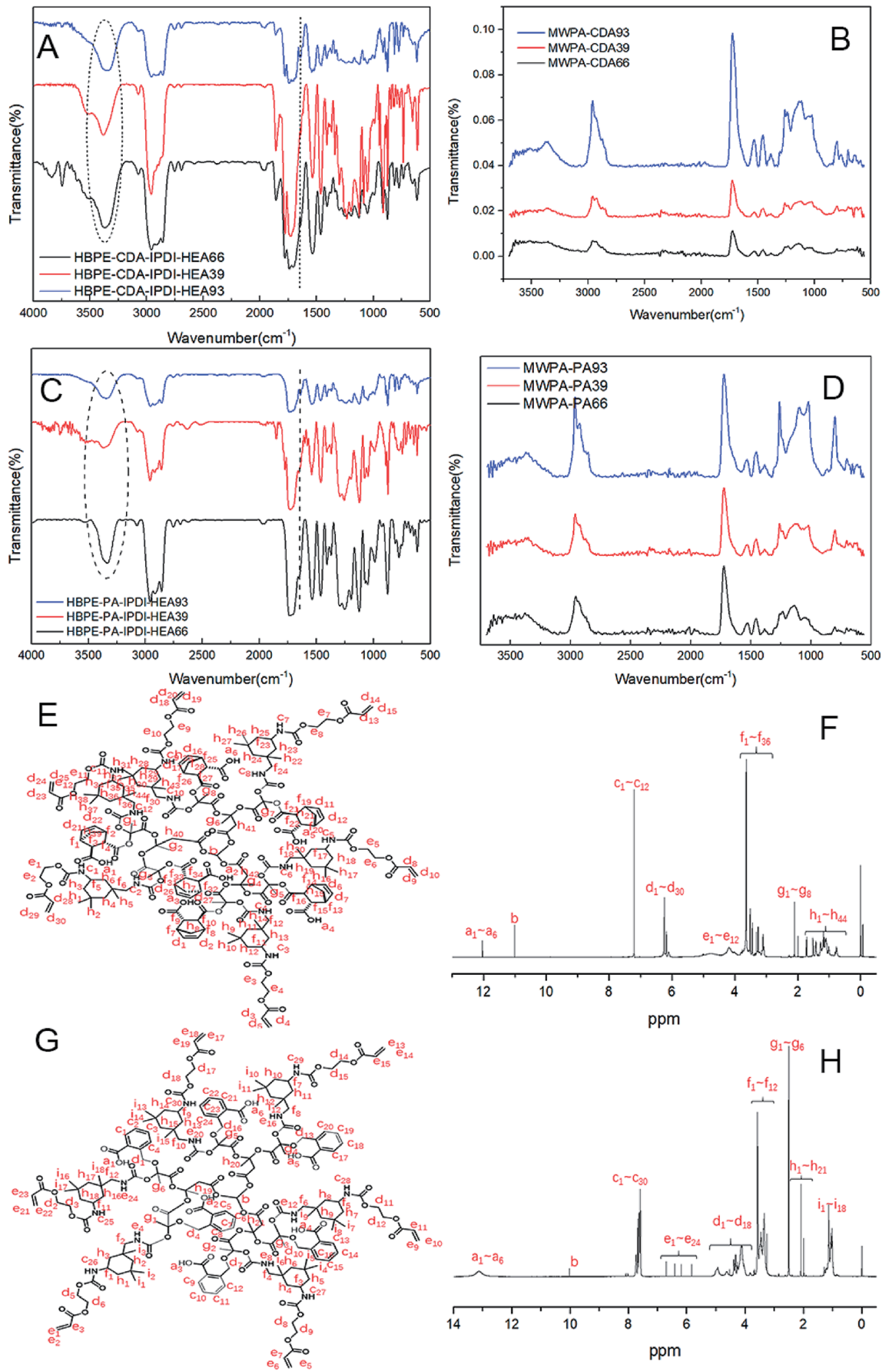

Fig. 4 FTIR spectra of the modified hyperbranched polyesters with CDA (A), the modified resin coatings with CDA after UV curing (B), the modified hyperbranched polyesters with PA $(C)$, and the modified resin coatings with PA after UV curing (D). The chemical structure $(E)$ and ${ }^{1} H-$ NMR spectrum of HBPE-CDA-IPDI-HEA66 (F). The chemical structure (G) and ${ }^{1} \mathrm{H}-\mathrm{NMR}$ spectrum of HBPE-PA-IPDI-HEA66 (H). 
2.5.5 Tensile properties. The tensile properties were measured using a multifunctional electronic strength tester TS2000 (America) with a tensile testing speed of $10 \mathrm{~mm} \mathrm{~min}^{-1}$. Samples of $80 \mathrm{~mm} \times 10 \mathrm{~mm}$ (length $\times$ width) were used for this evaluation. The samples were tailored into tensile test bars (10 $\times 80 \mathrm{~mm}^{2}$ ) with $0.5-1.0 \mathrm{~mm}$ thicknesses. The measurements needed to be performed at least three times. ${ }^{24,25}$

2.5.6 Scanning electron microscopy (SEM). The samples were sputter coated with gold prior to observation, and determined using an X-650 microscope (model JSM-5600LV) with a magnification range of 35-10 000 .

2.5.7 Other properties of the UV-cured EPD films. The gloss of the coating films was determined with an ETB-0686 gloss meter according to ASTMD523. $60^{\circ}$ glossiness was obtained for an average of at least three replicates. The hardness of surfaces was measured using Faber Castell 9000 pencils according to ASTM protocol D3363. The adhesion of the coatings on panels was measured using ASTM D3359. The impact of the coatings was measured via a membrane impacting tester QCJ-50 with a $1000 \mathrm{~g}$ hammer, after a coated tin sample had been placed directly below the impact hammer. The flexibility of the coated paints on panels was measured with the tester QTX according to ASTM D 4145-10. The anticorrosion of the coating was evaluated under harsh chemical conditions according to ASTM B-117. The samples were immersed in a $5 \% \mathrm{NaCl}$ solution ( $\mathrm{pH}$ : 6.5-7.2) at $40{ }^{\circ} \mathrm{C}$. The overall test time was about 7 days. ${ }^{26-28}$

\section{Results and discussion}

\subsection{Structural characterization of the modified} hyperbranched polyesters and acrylic resins

The modified hyperbranched polyesters with CDA or PA and the modified EPD coatings after UV curing were prepared and investigated with FTIR. The spectra of HBPE-CDA-IPDI-HEA in the range of the molar ratios $6: 6,3: 9$ and $9: 3$ are shown in Fig. 4(A). HBPE-CDA-IPDI-HEA was prepared through HBPE (Fig. S1 and S2 $\dagger$ ) grafting CDA and IPDI-HEA [line (a) in Fig. S3†]. The bands for HBPE-CDA-IPDI-HEA66, HBPE-CDAIPDI-HEA39 and HBPE-CDA-IPDI-HEA93 are located at 1640 and $1550 \mathrm{~cm}^{-1}$, derived from the unsaturated hyperbranched oligomers with NCO-terminated IPDI-HEA, and there is a broad peak at around $3400 \mathrm{~cm}^{-1}$ due to the hydroxyls and amines. The acrylic matrix copolymers [line (b) of Fig. S3†] were synthesized via radical polymerization and inserted with IPDI-HEA for further UV curing. The final UV-curable EPD coatings were obtained for copolymerization with acrylic matrix copolymers and HBPE-CDA-IPDI-HEA after UV curing, and were investigated with FTIR. Typical spectra of the modified UV-curable EPD coatings (named MWPA-CDA or MWPA-PA) are shown in Fig. 4(B). As for MWPA-CDA, it was difficult to detect the typical peaks from the $-\mathrm{CH}=\mathrm{CH}_{2}$ groups of IPDI-HEA, which indicated that this reaction may have been be achieved. In the same way as with HBPE-CDA-IPDI-HEA and MWPA-CDA, HBPE-PA-IPDIHEA and MWPA-PA were prepared and investigated using FTIR. The spectra of HBPE-PA-IPDI-HEA and MWPA-PA for the molar ratios $6: 6,3: 9$ and $9: 3$ are depicted in Fig. 4(C) and (D).

Fig. 4(E) and (F) show the chemical structure of HBPE-CDAIPDI-HEA66 and its corresponding ${ }^{1} \mathrm{H}-\mathrm{NMR}$ spectrum, respectively. The chemical structure and ${ }^{1} \mathrm{H}$-NMR spectrum of HBPE-PA-IPDI-HEA66 are depicted in Fig. $4(\mathrm{G})$ and $(\mathrm{H})$. The consumption of the hydroxyl group in HBPE after the grafting reaction was implied by the weak signal in the range from 5.8 to $6.4 \mathrm{ppm}$ which is ascribed to $-\mathrm{C}=\mathrm{C}$ - bonds. In addition, the peaks corresponding to the units of various groups were also observed in the spectrum. The weak peaks at 12.1 and $13.2 \mathrm{ppm}$ were attributed to the -COOH groups of HBPE-CDA and HBPE$\mathrm{PA}$, and those at 7.1-7.8 ppm were due to the $-\mathrm{NH}$ groups which were part of the segments in both and the $-\mathrm{CH}$ - group of the benzene ring in HBPE-PA. Fig. S4-S7 $†$ also show typical ${ }^{1} \mathrm{H}-\mathrm{NMR}$ spectra of HBPE-CDA-IPDI-HEA39, HBPE-PA-IPDI-HEA39, HBPE-PA-IPDI-HEA39 and HBPE-PA-IPDI-HEA93.

\subsection{Particle-size control}

Fig. 5 depicts the change in carboxylic group content and the diameter of the aggregates for MWPA-CDA and MWPA-PA. By varying the ratios of the carboxylic groups on WPA, MWPACDA39, MWPA-CDA66 and MWPA-CDA93, the particle sizes of the aggregates was found to be 43.8, 91.3, 106 and $122 \mathrm{~nm}$, respectively. The particle sizes of MWPA-PA were notably similar to those of MWPA-CDA, which were 91.3, 106 and $164 \mathrm{~nm}$. The diameter of the aggregates can be modulated
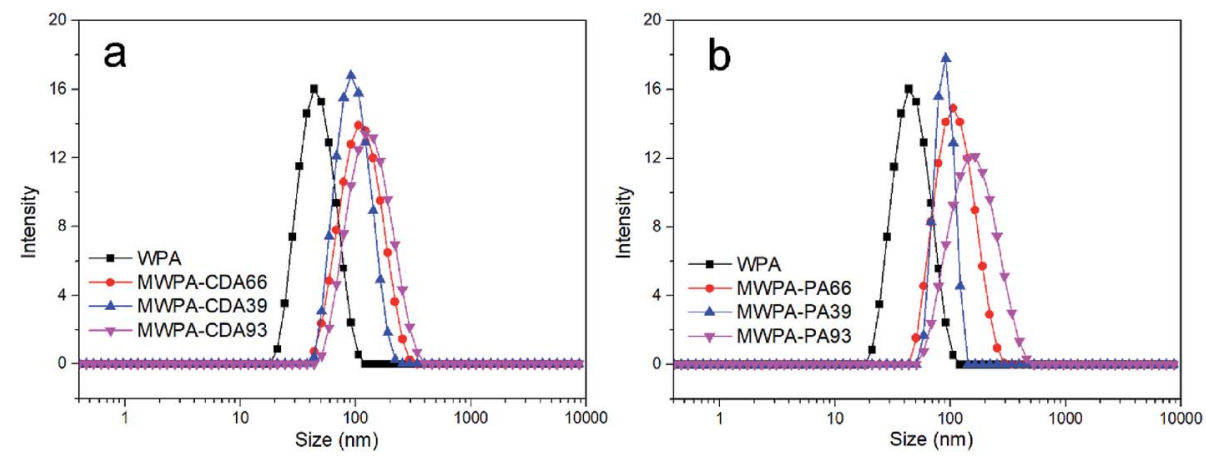

Fig. 5 The particle size distribution of the modified polyacrylate dispersions. (WPA is the unmodified acrylate dispersion; MWPA-CDA and MWPA-PA were modified acrylate dispersions with 30 wt\% CDA or PA, the molar ratios were $3: 9,6: 6$ and $9: 3$ ). 
based on the viscosity of the precursor via methods such as altering the emulsifying speed and dose of emulsifier. Aside from this, the ratios of the hydrophilic groups governed primarily changes in particle size distribution. ${ }^{23,29}$ It can therefore be assumed that the ionic content was inversely proportional to the average particle size. In waterborne dispersions, this was consistent with previous reports that hydrophilic aggregates typically had a smaller particle size. ${ }^{12}$ The molecular weight size and distribution were also closely related to the particle size, as shown in Fig. S8 and Table S1. $\dagger$

The zeta potential data for the modified polyacrylate dispersions is shown in Table S2. $\dagger$ According to the electrical double layer model, the ionic group would be mostly situated on the surface of the aggregates, while the segments would be located inside the particles. ${ }^{30}$ A balance is established between the electrostatic forces and diffusion forces in the electric double layer so that from formation of the electric double layer, since the same latex particles have the same charges, while the same charges repel, the latex particles can be stably suspended in water. As for the particle size distribution, the electrophoretic dispersion did not undergo significant phase separation, and it was speculated that the carboxyl group in the modified hyperbranched polymer structure was water-soluble and would neutralize the amino group in the pure WPA resin. An increase in hydrophilic group content could lead to an increase in the amount of charge on the surface of particle, and the smaller particle size caused an increase in the charge density on the surface of the particle. Therefore, as the hydrophilic group content increased, the zeta potential (absolute value) became larger.

\subsection{The photo-curing behavior of the UV-cured EPD coatings}

Darocur 1173 (1.5 wt\% relative to the total mass) was employed as the photoinitiator, and HDDA (94.5 $\mathrm{wt} \%$ relative to the total mass) was selected as a reactive diluent to decrease the concentration of the reactants and increase the photo-curing efficiency. The EPD coatings were further cross-linked under UV irradiation after evaporation of the moisture.

The curing kinetic equation of the UV system is determined according to the following equation: ${ }^{31-33}$

$$
R_{\mathrm{p}}=\frac{\mathrm{d} \alpha}{\mathrm{d} t}=\frac{\mathrm{d} H / \mathrm{d} t}{\Delta H_{\text {total }}}=\frac{\mathrm{d} H / \mathrm{d} t}{C \times H_{0}}
$$

where $\alpha$ represents the degree of the curing reaction, $R_{\mathrm{p}}$ and $\mathrm{d} \alpha /$ $\mathrm{d} t$ represent the polymerization rate, $\mathrm{d} H / \mathrm{d} t$ represents the heat flow, $\Delta H_{\text {total }}$ represents the theoretical heat of the complete reaction, and $H_{0}$ represents the molar exothermic heat. The $H_{0}$ value for an acrylic double bond is $80.2 \mathrm{~kJ} \mathrm{~mol}^{-1} \cdot{ }^{31}$ The conversion of acrylate groups can be found using the following equation: ${ }^{34,35}$

$$
\alpha=\frac{\Delta H_{t}}{\Delta H_{\text {total }}}
$$

where $\Delta H_{t}$ represents the reaction heat evolved at time $t$. The kinetic reaction rate equation was determined by Decker with the equation ${ }^{36}$

$$
R\left(\% \mathrm{~s}^{-1}\right)=\frac{\alpha_{t 2}-\alpha_{t 1}}{t_{2}-t_{1}}
$$

where $R$ represents the extent of photo-polymerization $\left(\% \mathrm{~s}^{-1}\right)$. $\alpha_{t 2}$ and $\alpha_{t 1}$ represent the corresponding values on the sigmoid curve at a given time $\left(t_{2}\right.$ and $\left.t_{1}\right)$.

Fig. 6(a) shows the polymerization rates of WPA bearing different molar amounts of CDA. Fig. 6(b) depicted conversion versus time plots for the UV-systems. The double bond reaction of acrylate quickly increased within $10 \mathrm{~s}$ and then the peak maximum decreased sharply. The experimental results provided in Table $\mathrm{S} 3 \uparrow$ demonstrate that the photo-sensitized hyperbranched modified compound in the system obviously has enhanced conversion and polymerization reactivity, which was attributed to grafting different levels of double bonds along with more cross-linking reactions. The maximum rate of polymerization for the unmodified acrylic formulation (WPA) was at 5.0 s. MWPA-CDA66 had a relatively low $R_{\mathrm{p}}$, but the $R_{\mathrm{p}}$ of the modified acrylic formulations (MWPA-CDA39 and MWPACDA93) were higher than that of WPA, which had almost the same rate of polymerization.

It is well known that during a reaction process, the mobility of polymers strongly influences conversion efficiency in a UV curing system. High viscosity systems could hamper full curing because of the immobility of acrylic groups. ${ }^{\mathbf{1 1}}$ Based on the lower viscosity of the hyperbranched structure, the modified
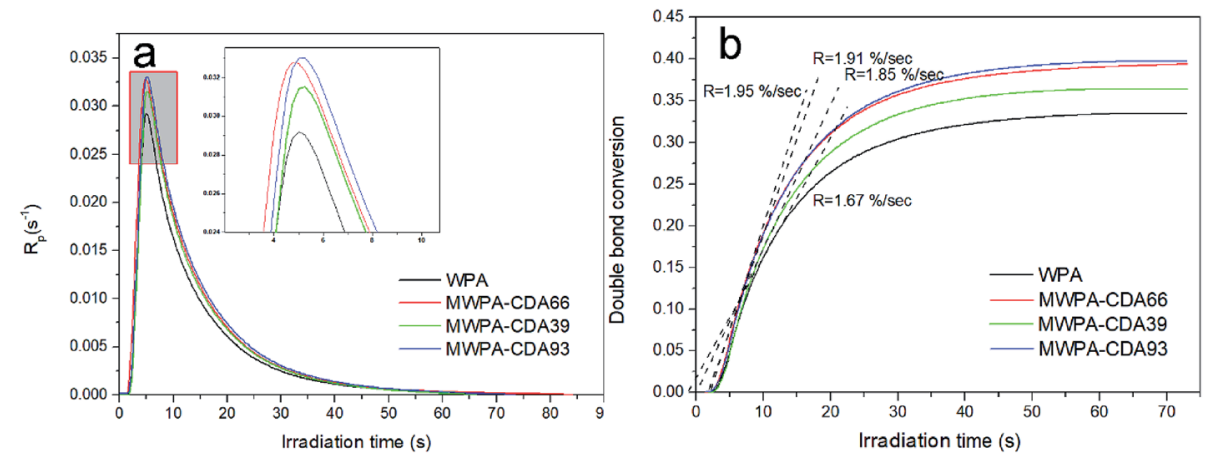

Fig. 6 The reaction rate of photopolymerization (a) and double bond conversion (b) curves for the photopolymerization of WPA, MWPA-CDA66, MWPA-CDA39 and MWPA-CDA93. $25^{\circ} \mathrm{C}$, light intensity $10 \mathrm{~mW} \mathrm{~cm}{ }^{-2}$ and an air atmosphere. 

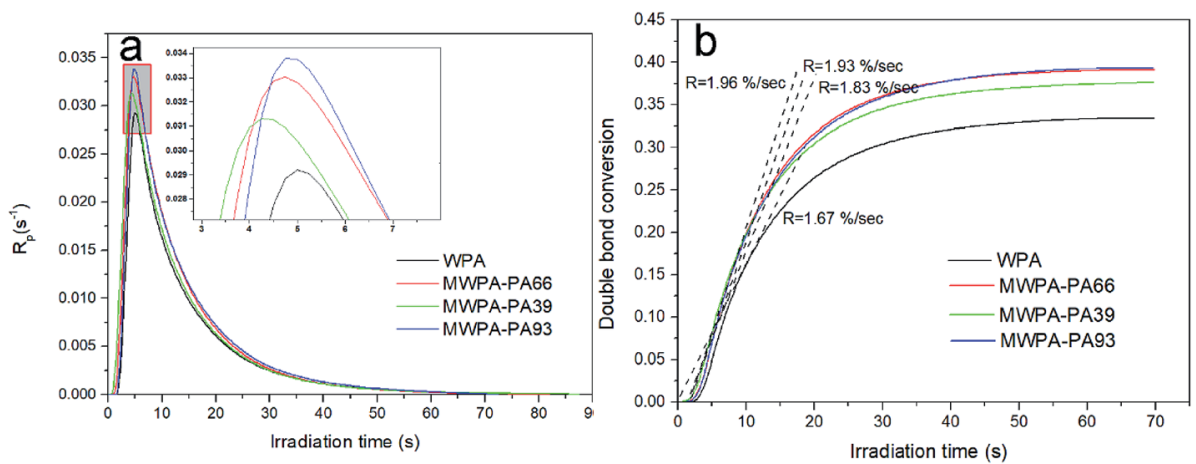

Fig. 7 The reaction rate of photopolymerization (a) and double bond conversion (b) curves for the photopolymerization of WPA, MWPA-PA66, MWPA-PA39 and MWPA-PA93. $25^{\circ} \mathrm{C}$, light intensity $10 \mathrm{~mW} \mathrm{~cm}^{-2}$ and an air atmosphere.

compounds containing double bonds demonstrated that the time scale of reaction diffusion was longer than that of the unmodified acrylic system (Fig. 6 and 7), which would in turn promote the conversion of the modified compounds (Tables S3 and S4 $\uparrow$ ). Tables S3 and $\mathrm{S} 4 \uparrow$ show that for both MWPA-CDA and MWPA-PA, the induction time decreased with increasing double bond content because of the augmentation of the number and mobility of the chains, and the rate of photo-polymerization could increase rapidly at the beginning of the reaction. ${ }^{37}$ The double bond content of the modified compounds is associated with the efficiency of photo-curing and their reactive activity. However, as shown by MWPA-PA in Fig. 6, intermolecular steric hindrance and termination radicals controlling the diffusion could occur, which eventually limits the efficiency of molecular polymerization. In Fig. 6(b) and 7(b), the double bond conversion of all the modified formulations was raised rapidly within $30 \mathrm{~s}$, which was due to the auto-acceleration effect (AAE) of methyl acrylate (MA). ${ }^{38}$

\subsection{Thermal stability of the UV-cured EPD films}

The glass transition temperature $\left(T_{\mathrm{g}}\right)$ with the varying double bond molar amounts of CDA and PA in WPA was measured and the results are shown in Fig. 8. The $T_{\mathrm{g}}$ values of WPA, MWPACDA66, MWPA-CDA39 and MWPA-CDA93 in Fig. 8(a) are $60.9{ }^{\circ} \mathrm{C}, 52.1{ }^{\circ} \mathrm{C}, 50.1{ }^{\circ} \mathrm{C}$ and $57.4^{\circ} \mathrm{C}$, respectively. Of these, the
$T_{\mathrm{g}}$ values of MWPA-CDA were lower than that of pure WPA, probably due to the incorporation of the acrylic cyclic structure and hyperbranched structure, which facilitated the mobility of the molecular chains and was compatible with soft segments, and thus the $T_{\mathrm{g}}$ values shifted to a low temperature region. ${ }^{39} \mathrm{In}$ addition, the $T_{\mathrm{g}}$ of MWPA-CDA93 with the $\mathrm{C}=\mathrm{C}$ bond content was higher than that of the other samples. Since the soft segments and the hard segments of the hyperbranched structure were more susceptible to phase separation, the glass transition region was broader. ${ }^{20}$ As for MWPA-PA with the double bond molar content of PA as shown in Fig. 8(b), the $T_{\mathrm{g}}$ values of WPA, MWPA-PA66, MWPA-PA39 and MWPA-PA93 were $60.9{ }^{\circ} \mathrm{C}, 64.5{ }^{\circ} \mathrm{C}, 72.1{ }^{\circ} \mathrm{C}$ and $66.3{ }^{\circ} \mathrm{C}$, respectively. The $T_{\mathrm{g}}$ of MWPA-PA was higher from containing some rigid segments, which changed with the ratio of soft and hard segments. Obviously, the $T_{\mathrm{g}}$ values increased with increasing unsaturated vinyl group and phenyl group content, which may result from the mobility of polymers becoming more difficult due to the presence of rigid segments and intramolecular crosslinking, and most of the polymers were trapped in dense networks. ${ }^{40}$

The thermogravimetric (TG) curves and differential thermogravimetric (DTG) analysis of waterborne UV-cured EPD coatings with CDA or PA under a $\mathrm{N}_{2}$ atmosphere are given in Fig. 9 and 10, and the temperature at the DTG peaks $\left(T_{\max }\right)$ and the char yield $\left(Y_{\mathrm{c}}\right)$ are listed in Tables S5 and S6. $\dagger$ The first

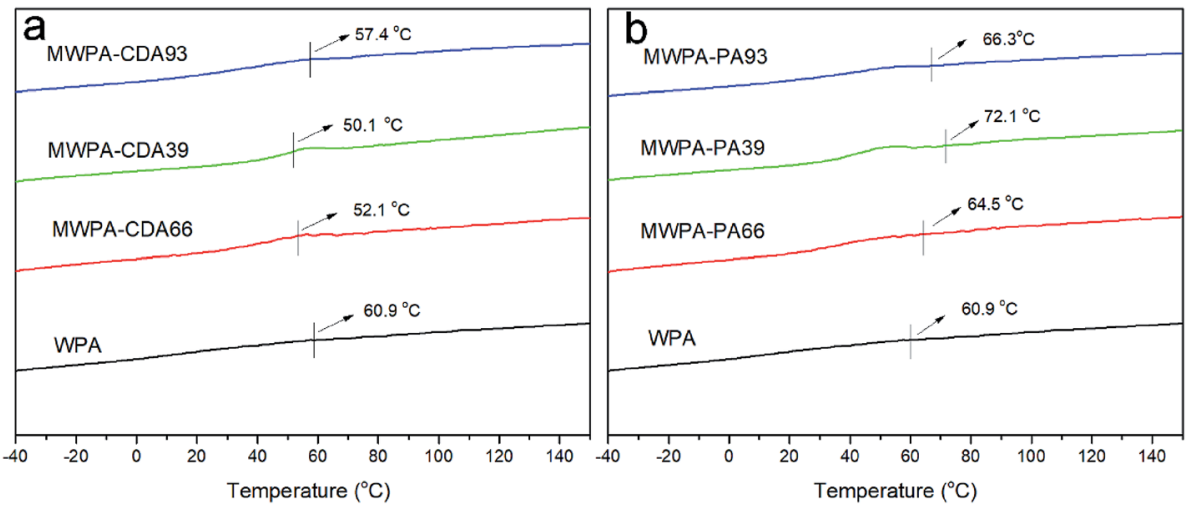

Fig. 8 DSC curves of waterborne UV-curable EPD coatings based on different double bond molar content of CDA (a) and PA (b). 

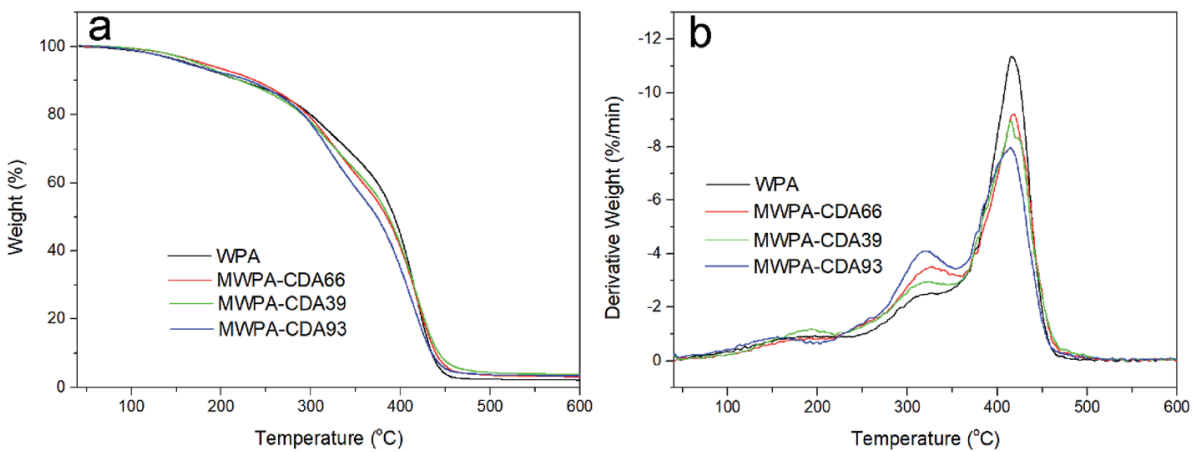

Fig. 9 TGA curves (a) and their corresponding DTG curves (b) of waterborne UV-curable EPD coatings with CDA in a nitrogen atmosphere at a heating rate of $10^{\circ} \mathrm{C} \mathrm{min}^{-1}$.
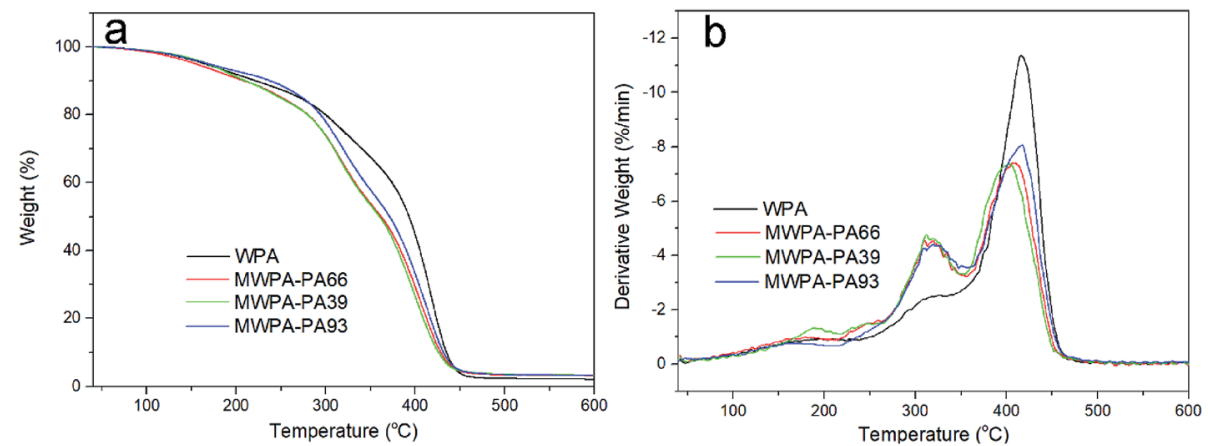

Fig. 10 TGA curves (a) and their corresponding DTG curves (b) of waterborne UV-curable EPD coatings with PA in a nitrogen atmosphere at a heating rate of $10^{\circ} \mathrm{C} \mathrm{min}^{-1}$.

thermal degradation below $150{ }^{\circ} \mathrm{C}$ was probably due to volatile organic solvent. Thereafter, all UV-curable EPD coatings exhibited similar thermal decomposition. For all of the coatings with CDA or PA, the first decomposition occurred at, with a corresponding maximum decomposition rate at, around $194^{\circ} \mathrm{C}$ for the decomposition of the urethane groups in the hard segments (HEA-IPDI). ${ }^{41,42}$ However, MWPA-CDA93 and MWPAPAP3 possessed lower decomposition temperatures, probably due to the grafting of more urethane groups in the structure. The second step of degradation (around $330{ }^{\circ} \mathrm{C}$ ) mostly correlated with decomposition of the ester groups in the segments.
The mass loss of MWPA-CDA and MWPA-PA was close to $40 \%$, which was attributed to there being more polyester in the grafted structure. As shown in Tables S5 and S6, $\dagger$ the high levels of soft segments in the molecular structure were conducive to their stability at high temperatures and reduced the initial decomposition rate. ${ }^{39}$ The third stage of degradation was around $415{ }^{\circ} \mathrm{C}$ from decomposition of the imide structures. ${ }^{43,44}$ In the range $150-450{ }^{\circ} \mathrm{C}$, there was nearly $95 \%$ weight loss; it had completely degraded. This probably correlated with the degradation of network structures and phenyl groups. ${ }^{41}$ Tables S5 and S6 $\dagger$ also exhibit that the $Y_{\mathrm{c}}$ of the coatings bearing CDA
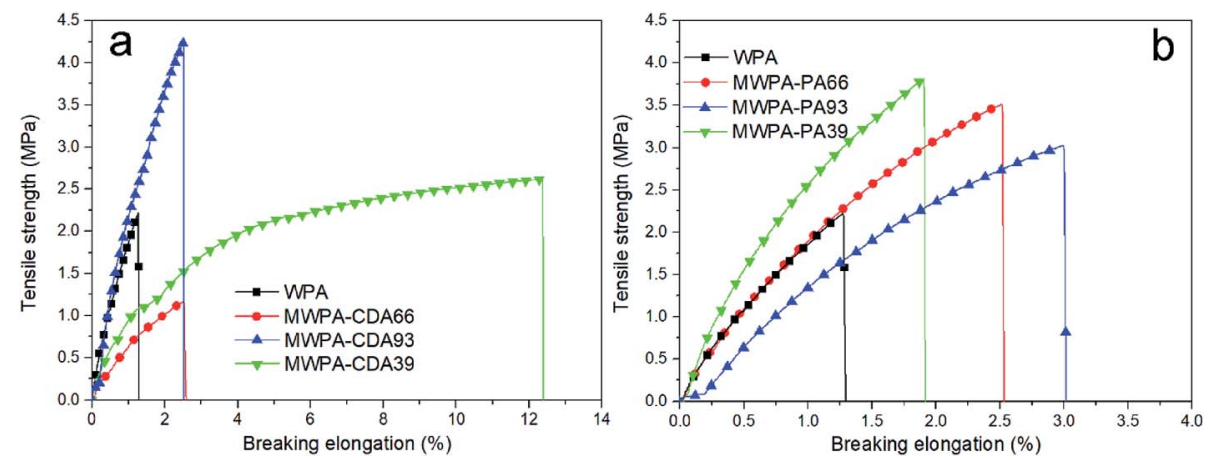

Fig. 11 Tensile stress-strain curves of waterborne UV-curable EPD coating films with different molar content of CDA or PA. 

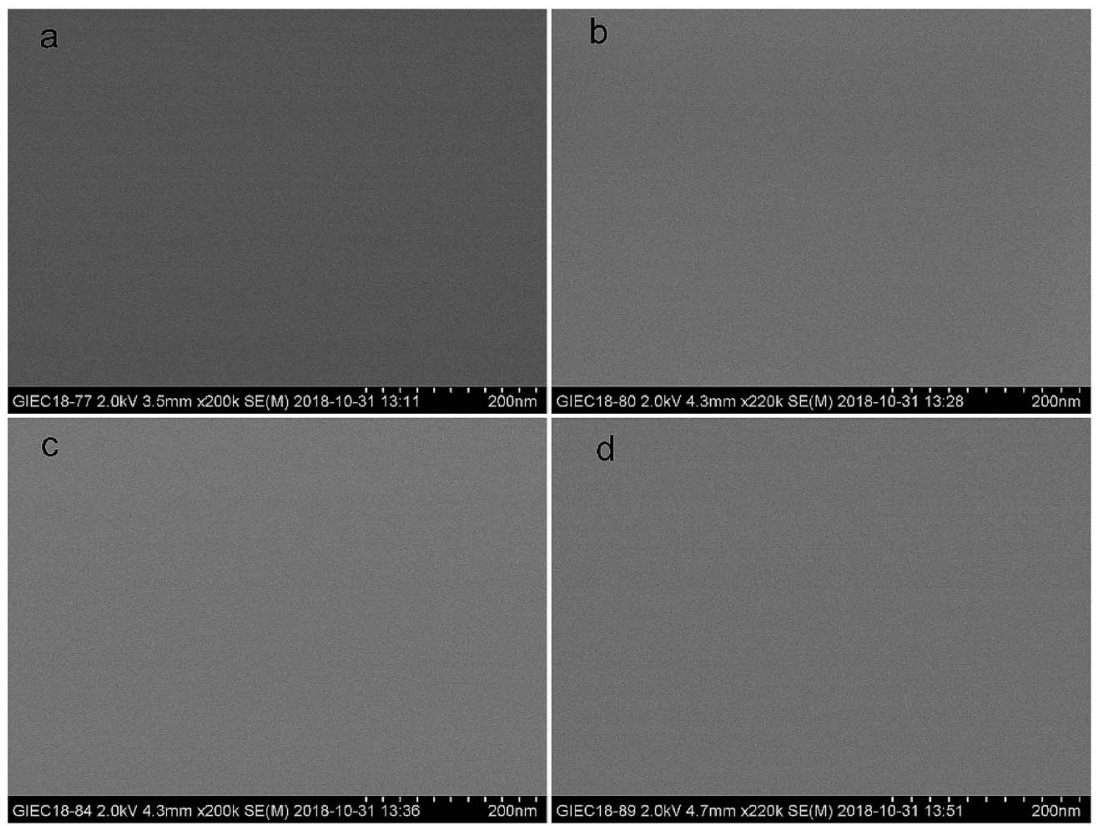

Fig. 12 SEM images of waterborne UV-curable EPD films with different molar amounts of CDA. (a) Pure acrylic coatings (WPA), scale: 200 nm; (b) MWPA-CDA66, scale: 200 nm; (c) MWPA-CDA39, scale: 200 nm; (d) MWPA-CDA93, scale: $200 \mathrm{~nm}$.

or PA was higher than that of the unmodified WPA. Therefore, UV-curable EPD coatings with CDA or PA presented excellent thermal stability, which is mainly attributed to successful polymerization of more unsaturated vinyl groups via UV radiation and the increase in cross-linking density.

\subsection{Mechanical properties}

Fig. 11 illustrates typical tensile curves of UV-curable EPD coatings with different molar content of CDA or PA, which is summarized in Table S7. $\dagger$ All the curves behave in line with a brittle nature with no yield stress point, which is analogous to the theoretical Gaussian network. ${ }^{45,46}$ UV-curing of the hyperbranched structure resulted in high crosslinking density in the system, a high tensile modulus and low elongation at the break of the coatings. As for MWPA-CDA, the tensile strength varied from 2.22 to $4.24 \mathrm{MPa}$ when the unsaturated acrylic chain molar content was increased. While the double bond molar ratio of MWPA-CDA reached $9: 3$, the unsaturated $\mathrm{C}=\mathrm{C}$ double bond increased, and then excessive cross-linking hampered the mobility of the polymer segments, so that the tensile strength of the UV-cured EPD system was enhanced. ${ }^{47}$ The breaking elongation sharply increased with increasing

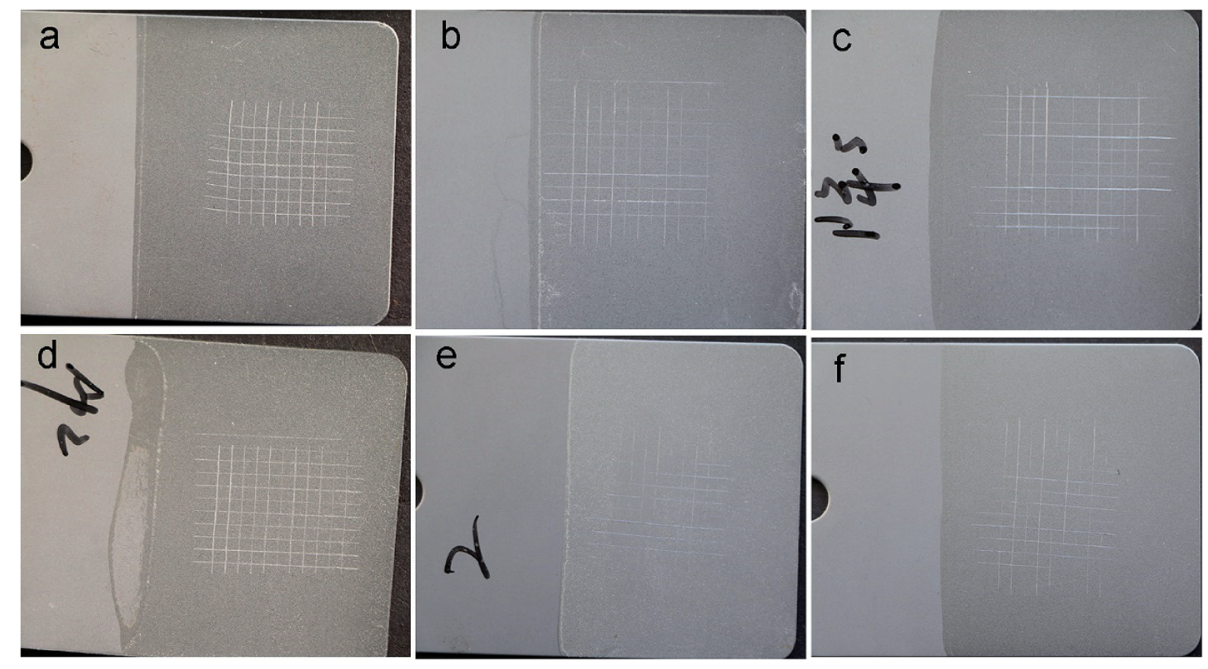

Fig. 13 Adhesion tests on UV-curable EPD coatings with different molar content of CDA or PA. A phosphating plate was used as the substrate, and the distance between each line was 2 mm. (a) MWPA-CDA66; (b) MWPA-CDA39; (c) MWPA-CDA93; (d) MWPA-PA66; (e) MWPA-PA39; (f) MWPA-PA93. 

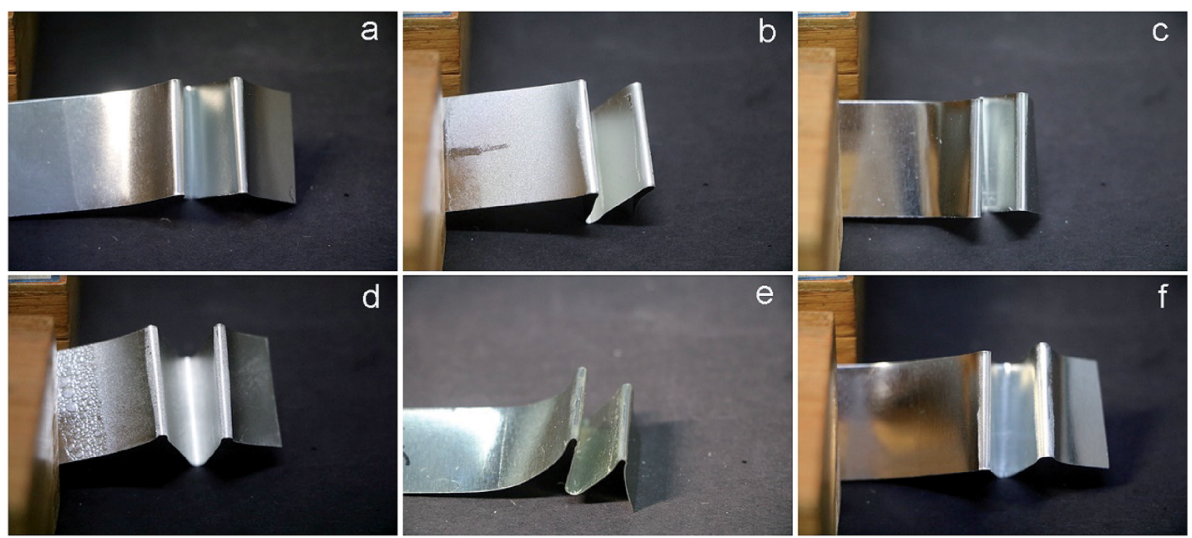

Fig. 14 Flexibility of UV-curable EPD coatings with different molar content of CDA or PA. A tin plate as the substrate was recorded after it had been subjected to bending. (a) MWPA-CDA66; (b) MWPA-CDA39; (c) MWPA-CDA93; (d) MWPA-PA66; (e) MWPA-PA39; (f) MWPA-PA93. Degree of flexibility test: $1 \mathrm{~mm}$.

flexible alkyl chain molar content for CDA, and then rapidly decreased. This could be explained by its molecules containing both unsaturated acrylic chains and dominant flexible alkyl segments. Hence, the UV-cured EPD coating films with MWPA-CDA39 were more ductile. ${ }^{48}$ For MWPA-PA, which had similar tendencies to MWPA-CDA, with increasing molar content of unsaturated acrylic chains, higher maximum load and stress were achieved at the expense of a decrease in the breaking elongation. ${ }^{49}$ Table S7 also demonstrates that the breaking elongations of MWPA-PA were at the low level of $1.91-3.0 \%$. The breaking elongations being at a low level was attributed to the structure with the benzene rings possessing rigidity. ${ }^{48}$

\subsection{Other physical performance aspects of the UV-curable EPD films}

SEM measurements were used for surface microtopography analysis of the UV-cured EPD coating films and the results can be seen in Fig. 12 and S9. $\dagger$ The surface of all the films with CDA and the partial films with PA were smooth, without cracks, and there was no obvious phase separation. This meant that the system had formed a crosslinked network with no macrophase separation between soft and hard segments under UV-curing. ${ }^{32}$ Many grooves were observed on the surface of MWPA-PA39 and it might be that the excessive rigid benzene rings hampered the efficiency of the UV-curable coatings, leading to incomplete curing. ${ }^{50}$

The general performance of the UV-curable EPD films were summarized in Table S8. $\dagger$ The coatings with a uniform thickness $(30 \mu \mathrm{m})$ possessed good compatibility. The pencil hardness of the coatings bearing MWPA-CDA39 was slightly decreased to $\mathrm{HB}$, which was ascribed to the overall characteristics dominated by the flexible chains. Conversely, the pencil hardness of films bearing MWPA-PA39 increased to $3 \mathrm{H}$, which resulted from incorporation of rigid benzene rings in the polymer. However, the higher mechanical properties were obtained at the expense of a reduction in the glossiness of the UV-curing film. The glossiness could be increased by increasing the content of monomers with a higher glass-transition temperature, but an evident drawback was that if the density of cross-linking points in the coating exceeded a certain level, minor cracks in the film could occur, resulting in relative roughness in all the films. ${ }^{51}$
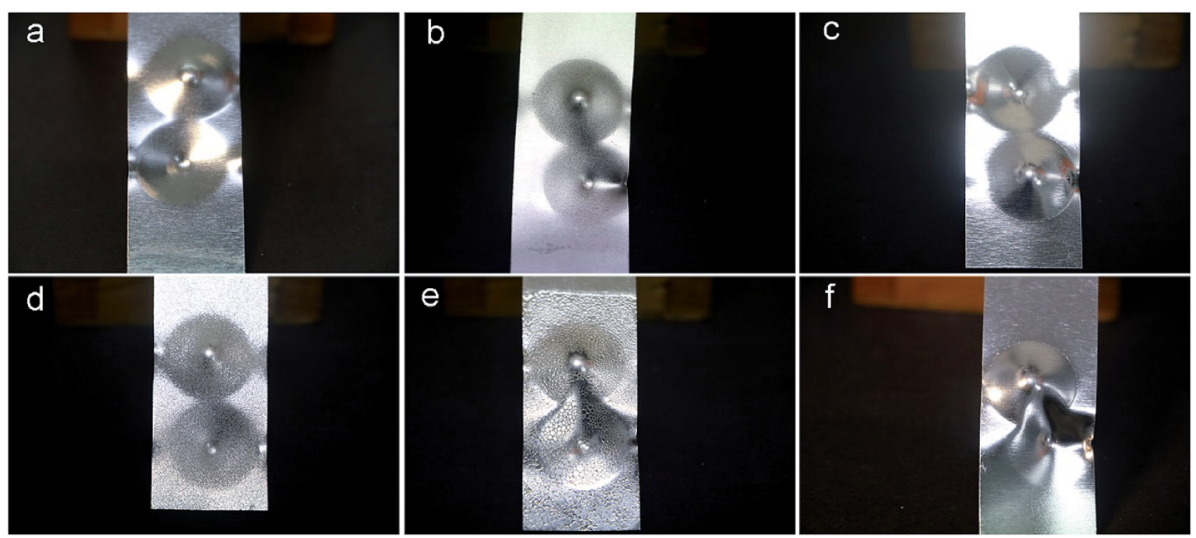

Fig. 15 The front and opposite sides of UV-curable EPD coatings with different molar content of CDA or PA, which were coated on tin plates after the impact experiments. (a) MWPA-CDA66; (b) MWPA-CDA39; (c) MWPA-CDA93; (d) MWPA-PA66; (e) MWPA-PA39; (f) MWPA-PA93. 

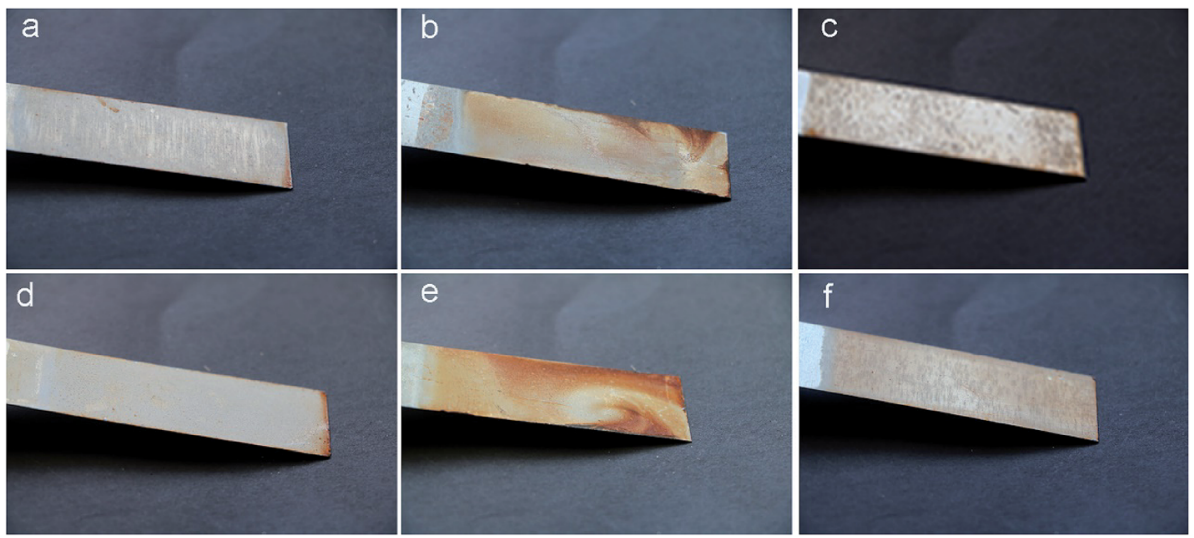

Fig. 16 Appearance of the corroded UV-curable EPD coating sample surfaces with different molar content of CDA or PA. (a) MWPA-CDA66; (b) MWPA-CDA39; (c) MWPA-CDA93; (d) MWPA-PA66; (e) MWPA-PA39; (f) MWPA-PA93.

The adherence of UV-curing EPD coating was further evaluated using ASTM D3359 standard and is shown in Fig. 13 and S10. $\dagger$ For most of the coating films, there was a slight decrease in adhesion degree compared to the pure acrylic coatings (WPA) of $5 \mathrm{~B}$, except that MWPA-PA39 was reduced to $2 \mathrm{~B}$, but it had little effect on its industrial applications. A uniform coating surface could increase the contact area and intermolecular interactions with the phosphating plate, thereby increasing its adhesion. The rough morphology weakened the adhesion. ${ }^{43,52}$ Fig. 14 and S11 $\uparrow$ illustrate the flexibility of the UV-curable EPD coatings with different molar content of CDA or PA, after the test plate was bent 180 degrees, the surface coating remained attached to the test plate with no cracking or pull off. The UVcurable EPD coating films with CDA seemingly exhibited a great appearance compared to the other films with PA. Due to the flexible structure in norbornene dianhydride, the movement and diffusion of polymer segments was carried out via conformational changes through rotation within single-bonds. ${ }^{42}$ As for MWPA-PA, some tiny cracks were observed in the surface of the films. Despite the hyperbranched reinforcing properties in the structure, the excessively rigid phenyl structures and crosslinking density result in a decrease in flexibility. Furthermore, the impact tests of UV-cured EPD coatings with different molar content of CDA or PA, were carried out on opposite sides of the plates with a $1000 \mathrm{~g}$ hammer (Fig. 15 and S12†). The results indicated that there was no evidence of weakening adhesion or having caused rupture to any noticeable degree. Obviously, the introduction of hyperbranched structures had a great influence on the flexibility and toughness of the coatings. ${ }^{53,54}$

Fig. 16 and $\mathrm{S} 13 \dagger$ display the photographs of corroded sample surfaces with different molar content of CDA or PA. The most modified samples coated on tin plate exhibited outstanding corrosion resistance. The chemical corrosion resistance may be attributed to the shielding of the coatings from the NaCl solution. Whilst the coating with MWPA-CDA39 showed appreciable degradation, MWPA-PA39 was covered by rust. The highly crosslinked networks were more resistant to corrosion. The place where the rust was covered was mainly concentrated on the marginal parts due to poor adhesion there to the coatings.

\section{Conclusion}

Some modified hyperbranched polyesters with varying molar content of CDA or PA were synthesized, and then incorporated into pure acrylic WPA. The final coatings were applied onto tin plates via an aqueous EPD strategy and UV curing. With increasing CDA and PA content, the diameter of the aggregates sharply increased from 43.8 to $164 \mathrm{~nm}$. Photo-DSC kinetic studies indicated that UV curing is an automatic acceleration process. The reaction rate of photopolymerization $\left(R_{\mathrm{p}}\right)$ and the double bond conversion increased with an increase in active unsaturated double bond content despite the steric hindrance of the benzene rings. The $T_{\mathrm{g}}$ of the resin was in the broad range $50-70{ }^{\circ} \mathrm{C}$. The coatings with a high content of CDA and PA exhibited higher thermal stability with char yields above $3.25 \%$. The prepared UV-curable waterborne EPD coating films had excellent tensile properties and low breaking elongations, indicating that more crosslinking points had been generated in the film-forming process, and that the intermolecular interactions had been improved. The surface morphology of the coatings was smooth with no evidence of phase separation or cracking. The coatings had outstanding tolerance to scratches and impact, and can withstand bending to $1 \mathrm{~mm}$. Moreover, the coated tin plates exhibited remarkable resistance against chemical corrosion; their surfaces were covered with no damage after immersion in $\mathrm{NaCl}$ solution at $40{ }^{\circ} \mathrm{C}$ over 7 days.

\section{Conflicts of interest}

There are no conflicts to declare.

\section{Acknowledgements}

The study was financially supported by Natural Science Foundation of Guangdong Province (Grant No. 2018A030313483, Grant No. 2018A030313235 and Grant No. 2018A030310349) and Foundation for High-level Talents in Qiannan Normal University for Nationalities [qnsyrc201706]. 


\section{References}

1 R. G. Hu, S. Zhang, J. F. Bu, C. J. Lin and G. L. Song, Prog. Org. Coat., 2012, 73, 129-141.

2 L. Besra and M. Liu, Prog. Mater. Sci., 2007, 52, 1-61.

3 L. Cordero-Arias, S. Cabanas-Polo, J. Gilabert, O. M. Goudouri, E. Sanchez, S. Virtanen and A. R. Boccaccini, Adv. Appl. Ceram., 2014, 113, 42-49.

4 A. R. Boccaccini and I. Zhitomirsky, Curr. Opin. Solid State Mater. Sci., 2002, 6, 251-260.

5 S. Somarajan, S. A. Hasan, C. T. Adkins, E. Harth and J. H. Dickerson, J. Phys. Chem. B, 2008, 112, 23-28.

6 O. O. Van der Biest and L. Vandeperre, Annu. Rev. Mater. Sci., 1999, 29, 327-352.

7 H. Mao, K. Wang, C. Wang and M. Wu, J. Adhes. Sci. Technol., 2014, 28, 186-200.

8 T. Wang, S. Qi, B. Ren and Z. Tong, J. Appl. Polym. Sci., 2008, 107, 4036-4042.

9 H. V. Patel, J. Raval and P. Patel, Arch. Appl. Sci. Res., 2009, 1, 294-305.

10 Q. Zhang, C. Huang, H. Wang, M. Hu, H. Li and X. Liu, RSC Adv., 2016, 6, 107942-107950.

11 R. Oliver and F. Andreas, Prog. Org. Coat., 2002, 45, 239-247.

12 Y. B. Kim, H. K. Kim, J. K. Yoo and J. W. Hong, Surf. Coat. Technol., 2002, 157, 40-46.

13 Y. B. Kim, J. M. Park, H. K. Kim and J. W. Hong, Polym. Bull., 2001, 47, 313-319.

14 Y. B. Kim, H. K. Kim and J. W. Hong, J. Appl. Polym. Sci., 2006, 102, 5566-5570.

15 A. Hult, M. Johansson and E. Malmström, in Branched Polymers II, ed. J. Roovers, Springer Berlin Heidelberg, Berlin, Heidelberg, 1999, pp. 1-34, DOI: 10.1007/3-54049780-3_1.

16 Y. Zheng, S. Li, Z. Weng and C. Gao, ChemInform, 2015, 44, 4091-4130.

17 J. Zhang, H. Xu, L. Hu, Y. Yang, H. Li, C. Huang and X. Liu, ACS Omega, 2017, 2, 7546-7558.

18 W. Yin, X. Zeng, H. Li, X. Lin, B. Ren and Z. Tong, J. Coat. Technol. Res., 2013, 10, 57-64.

19 R. Liu, X. Zhang, J. Zhu, X. Liu, Z. Wang and J. Yan, ACS Sustainable Chem. Eng., 2015, 3, 1313-1320.

20 A. Asif, L. Hu and W. Shi, Colloid Polym. Sci., 2009, 287, 1041-1049.

21 C. B. Fanska, T. J. Byerley and J. D. Eick, J. Chromatogr., 1991, 537, 357-364.

22 S. R. Liao, Y. Wei, Y. Q. Zhang, M. Zhang and G. F. Feng, Adv. Mater. Res., 2012, 418-420, 13-17.

23 A. Asif, C. Huang and W. Shi, Colloid Polym. Sci., 2004, 283, 200-208.

24 Y. Feng, H. Liang, Z. Yang, T. Yuan, Y. Luo, P. Li, Z. Yang and C. Zhang, ACS Sustainable Chem. Eng., 2017, 5, 7365-7373.

25 P. Li, S. Ma, J. Dai, X. Liu, Y. Jiang, S. Wang, J. Wei, J. Chen and J. Zhu, ACS Sustainable Chem. Eng., 2017, 5, 1228-1236.

26 L. Calabrese, E. Proverbio, G. D. Bella, G. Galtieri and C. Borsellino, Eng. Struct., 2015, 82, 33-43.
27 S. Hiromoto, Mater. Trans., 2012, 53, 700-706.

28 B. Xue, Y. Jiang, F. Li, M. Xia, M. Sun, D. Liu, X. Zhang and L. Yu, J. Appl. Polym. Sci., 2010, 116, 3480-3488.

29 A. Asif, W. Shi, X. Shen and K. Nie, Polymer, 2005, 46, 1106611078.

30 D. Henderson, Prog. Surf. Sci., 1983, 13, 197-224.

31 G. R. Tryson and A. R. Shultz, J. Polym. Sci., Polym. Phys. Ed., 1979, 17, 2059-2075.

32 J. Xu, Y. Jiang, T. Zhang, Y. Dai, D. Yang, F. Qiu, Z. Yu and P. Yang, Prog. Org. Coat., 2018, 122, 10-18.

33 J.-D. Cho and J.-W. Hong, Eur. Polym. J., 2005, 41, 367-374.

34 A. Palanisamy and B. S. Rao, Prog. Org. Coat., 2007, 60, 161169.

35 D. S. Esen, F. Karasu and N. Arsu, Prog. Org. Coat., 2011, 70, 102-107.

36 C. Decker and K. Moussa, J. Polym. Sci., Part A: Polym. Chem., 1990, 28, 3429-3443.

37 R. V. Ghorpade, S. M. Bhosle, S. Ponrathnam, C. R. Rajan, N. N. Chavan and R. Harikrishna, J. Polym. Res., 2012, 19, 9811.

38 Y. Huang, G. Ye and J. Yang, Prog. Org. Coat., 2015, 78, 28-34. 39 M. Li, F. Liu, Y. Li and X. Qiang, RSC Adv., 2017, 7, 1331213324.

40 Y. Huang, G. Ye and J. Yang, Prog. Org. Coat., 2015, 78, 28-34. 41 W. Han, B. Lin, H. Yang and X. Zhang, J. Appl. Polym. Sci., 2013, 128, 4261-4270.

42 H. Xiang, X. Wang, L. Xi, H. Dong, P. Hong, J. Su, Y. Cui and X. Liu, Prog. Org. Coat., 2017, 114, 216-222.

43 A. K. Mishra, R. Narayan, K. Raju and T. M. Aminabhavi, Prog. Org. Coat., 2012, 74, 134-141.

44 E. S. Džunuzović, S. V. Tasić, B. R. Božić, J. V. Džunuzović, B. M. Dunjić and K. B. Jeremić, Prog. Org. Coat., 2012, 74, 158-164.

45 H. Wang, Y. Niu, G. Fei, Y. Shen and J. Lan, Prog. Org. Coat., 2016, 99, 400-411.

46 J. M. Yeha, C. F. Hsieh, H. C. Yang and C. P. Wu, Eur. Polym. J., 2008, 44, 2777-2783.

47 H. Bakhshi, H. Yeganeh, A. Yari and S. K. Nezhad, J. Mater. Sci., 2014, 49, 5365-5377.

48 S. Li, X. Yang, K. Huang, M. Li and J. Xia, Prog. Org. Coat., 2014, 77, 388-394.

49 G. Rivero, L.-T. T. Nguyen, X. K. D. Hillewaere and F. E. Du Prez, Macromolecules, 2014, 47, 2010-2018.

50 G. Li, S. Jiang, Y. Gao, X. Liu and F. Sun, Ind. Eng. Chem. Res., 2013, 52, 2220-2227.

51 Y. Wu, H. Duan, Y. Yu and C. Zhang, J. Appl. Polym. Sci., 2001, 79, 333-336.

52 H. Xiang, X. Wang, G. Lin, L. Xi, Y. Yang, D. Lei, H. Dong, J. Su, Y. Cui and X. Liu, Polymers, 2017, 9, 552.

53 Y. H. Kim, J. Polym. Sci., Part A: Polym. Chem., 1998, 36, 16851698.

54 D. Konkolewicz, M. J. Monteiro and S. Perrier, Macromolecules, 2011, 44, 7067-7087. 